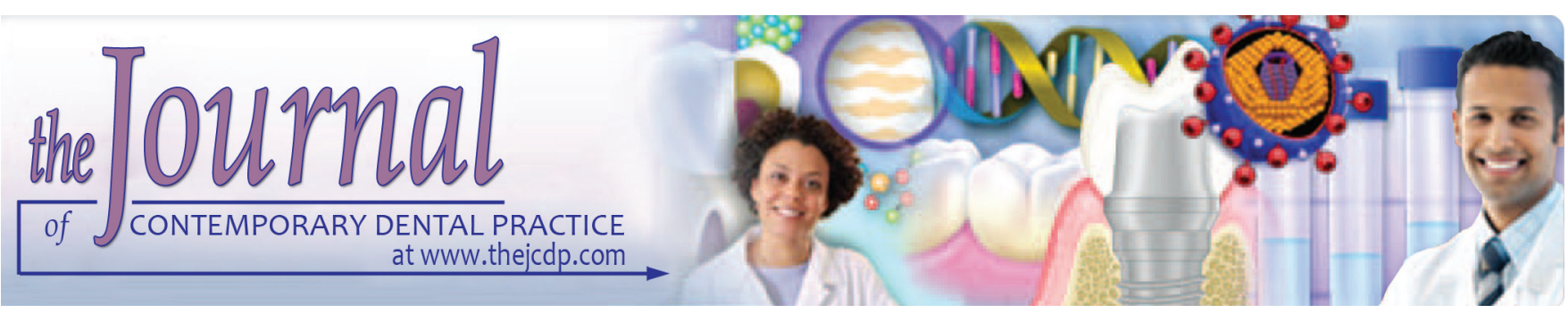

\title{
Marginal Bone Remodeling around healing Abutment vs Final Abutment Placement at Second Stage Implant Surgery: A 12-month Randomized Clinical Trial
}

${ }^{1}$ Nabih Nader, ${ }^{2}$ Maissa Aboulhosn, ${ }^{3}$ Antoine Berberi, ${ }^{4}$ Cordahi Manal, ${ }^{5}$ Ronald Younes

\begin{abstract}
Background: The periimplant bone level has been used as one of the criteria to assess the success of dental implants. It has been documented that the bone supporting two-piece implants undergoes resorption first following the second-stage surgery and later on further to abutment connection and delivery of the final prosthesis.
\end{abstract}

Objective: The aim of this multicentric randomized clinical trial was to evaluate the crestal bone resorption around internal connection dental implants using a new surgical protocol that aims to respect the biological distance, relying on the benefit of a friction fit connection abutment (test group) compared with implants receiving conventional healing abutments at secondstage surgery (control group).

Materials and methods: A total of partially edentulous patients were consecutively treated at two private clinics, with two adjacent two-stage implants. Three months after the first surgery, one of the implants was randomly allocated to the control group and was uncovered using a healing abutment, while the other implant received a standard final abutment and was seated and tightened to $30 \mathrm{Ncm}$. At each step of the prosthetic try-in, the abutment in the test group was removed and then retightened to $30 \mathrm{Ncm}$. Horizontal bone changes were assessed using periapical radiographs immediately after implant placement and at 3 (second-stage surgery), 6, 9 and 12 months follow-up examinations.

Results: At 12 months follow-up, no implant failure was reported in both groups. In the control group, the mean periimplant bone resorption was $0.249 \pm 0.362$ at $\mathrm{M} 3,0.773 \pm 0.413$ at

\footnotetext{
${ }^{1-3}$ School of Dentistry, Lebanese University, Beirut, Lebanon ${ }^{4}$ Medical School, Lebanese University, Beirut, Lebanon

${ }^{5}$ Faculty of Dental Medicine, Saint Joseph University Beirut Lebanon

Corresponding Author: Antoine Berberi, Professor, Department of Oral and Maxillofacial Surgery, School of Dentistry Lebanese University, Beirut, Lebanon, Phone: +9613731173 e-mail: anberberi@gmail.com
}

M6, $0.904 \pm 0.36$ at M9 and $1.047 \pm 0.395$ at M12. The test group revealed a statistically significant lower marginal bone loss of $20.88 \%$ at M3 $(0.197 \pm 0.262), 22.25 \%$ at M6 (0.601 \pm $0.386), 24.23 \%$ at M9 (0.685 \pm 0.341$)$ and $19.2 \%$ at M9 $(0.846$ $\pm 0.454)$. The results revealed that bone loss increased over time, with the greatest change in bone loss occurring between 3 and 6 months. Alveolar bone loss was significantly greater in the control condition than the test condition.

Conclusion: The results of this prospective study demonstrated the benefit of placing a prosthetic component with a stable connection at second-stage surgery, in terms of reduced marginal bone remodeling when compared with conventional procedure.

Clinical significance. The use of a stable connection in a healing component during try-in stages prior to final restoration placement leads to less periimplant marginal bone loss.

Keywords: Friction fit connection, Healing abutment marginal bone loss, Microgap.

How to cite this article: Nader N, Aboulhosn M, Berberi A, Manal C, Younes R. Marginal Bone Remodeling around healing Abutment vs Final Abutment Placement at Second Stage Surgery: A 12-month Randomized Clinical Trial. J Contemp Dent Pract 2016;17(1):7-15.

Source of support: Nil

Conflict of interest: None

\section{INTRODUCTION}

It has been well documented that the bone supporting two-piece implants undergoes resorption first following the second-stage surgery and later on further to abutment connection and delivery of the final prosthesis. ${ }^{1-3}$ The influence of implant type, one-piece or soft tissue level implants vs two-piece or bone-level implants has not been sufficiently documented in humans, and data from animal studies are controversial. 
In 'bone level' type of implants, the transmucosal component (the abutment) dedicated to soft tissue integration is a separate part from the implant body. The interface between the transmucosal component and the implant is generally located in the vicinity of the buccal bone level.

Abrahamsson et $\mathrm{al}^{4}$ demonstrated that the dimensions of the junctional epithelium and connective tissue are similar on both tissue and bone-level implants. In addition, their position relative to the bone crest was also comparable, with the soft tissue integration located on the smooth implant's neck on one-piece implants and at the abutment level on two-piece implants. While the possible reasons for early marginal bone loss have been extensively discussed, it remains a controversial issue. Bone reaction to the load, ${ }^{5}$ a microgap between implant and abutment, ${ }^{6}$ and polished implant neck $(\mathrm{IN})^{7}$ are some factors implicated in early periimplant bone loss.

In particular, the microgap and its influence on the formation of the biologic width has been also studied. ${ }^{8}$ The dimensions of the periimplant soft tissue, as evaluated by histometric measurements, are significantly influenced by the presence/absence of a microgap between the implant and the abutment, and the location of this microgap in relation to the bone crest. ${ }^{9}$ If the implant-abutment junction is positioned above the crest, the resorption of bone is significantly less than if it is positioned below the crest.

Preservation of periimplant hard and soft tissue remains a challenge. Different strategies are currently used to minimize bone resorption such as graft material and implant macro-geometry. The exposed rough surface of the implant combined to the presence of micro-threads could be a potential risk for a future bacterial colonization and a starting point for a progressive bone loss leading to a possible implant failure. On the contrary, the use of a stable abutment connection with minimum micro movement might help to reduce the microgap and establish a stable periimplant biological distance; this will lead to a minimum crestal bone resorption. At this point, microgrooves and full texturing will potentially prevent bone resorption after implant loading.

The authors hypothesized that the configuration of the healing abutment is a negative factor following second-stage surgery, as its design does not respect the biological width, and favors the presence of a microgap. This will lead to a bone loss up to $1.5 \mathrm{~mm}$ around the neck of the implant even in presence of microgrooves and full texturing.

The aim of this study was to evaluate the influence of a stable implant prosthetic component connection on crestal bone remodeling around the neck of the implant, placed at second-stage surgery. The goal of this new therapeutic protocol relied on the benefit of a friction fit connection that respects the biological distance during prosthetic try-in stages.

\section{MATERIALS AND METHODS}

\section{Study Design and Patient Selection}

The present study was a prospective, multicentric, randomized controlled clinical trial with a parallel-group study design.

From February 2012 to September 2013, 18 partially edentulous patients were selected and treated in two different private dental clinics.

This study was designed and conducted in full accordance with the World Medical Association Declaration of Helsinki, as revised in 2002. All patients signed a specific written informed consent form and they had the right to withdraw from the study at anytime.

The inclusion criteria included the following:

- Older than 18 years;

- Partially edentulous posterior maxilla and mandible;

- Extraction site at least 6 months; and

- Minimum bone height of $13 \mathrm{~mm}$; The exclusion criteria included

- Chronic systemic diseases;

- Radiation therapy in the cranio-facial region within the previous 12 months;

- Pregnant or lactating female patients;

- Smokers (>10 cigarettes per day);

- Teeth with acute infection at the sites;

- Patients presenting less than $3 \mathrm{~mm}$ of keratinized tissue on the site of implant placement;

- Patients with severe occlusal disorders;

- Unsuitable quantity of bone in the surgery site or need of bone augmentation procedures before implant placement.

Each patient received two adjacent $4.1 \mathrm{~mm}$ diameter implants, positioned in a partially edentulous posterior maxilla or mandible. One implant was considered as control (regular healing abutment) and the other one as test (friction fit short abutment).

\section{Surgical Technique}

Three days prior to stage 1 surgery and for a 2-week period, all patients were instructed to use $0.12 \%$ chlorhexidine mouthrinse twice daily. Antimicrobial prophylaxis was obtained using amoxicillin $1 \mathrm{gm}$ (Ospamox $1000 \mathrm{mg}$, Sandoz; Novartis, Basel, Basel-Stadt, Switzerland) twice daily for 6 days, starting 1 hour before surgery. A nonsteroidal anti-inflammatory diclofenac potassium $50 \mathrm{mg}$ 
(Cataflam 50; Novartis, Basel, Basel-Stadt, Switzerland) was also prescribed $100 \mathrm{mg}$ daily in two divided doses, starting 1 hour before surgery. Local anesthesia (2\% articaine/adrenaline 1:100,000) was used at the time of surgery.

Surgery began with a mid-crestal incision; a fullthickness flap was then elevated and the crestal ridge exposed. Following the manufacturer instructions, two full textured dental implants (Tapered Screw-vent ${ }^{\circledR}$, $11.5 \mathrm{~mm}$ length and $4.1 \mathrm{~mm}$ diameter; Zimmer Dental, Carlsbad, CA, USA) were placed in a submerged protocol and positioned at $0.5 \mathrm{~mm}$ beneath the bone crest (Fig. 1A). Patients were instructed to limit themselves to a soft diet for the first 3 weeks after surgery. Sutures were removed 7 days after surgery. No removable or fixed temporary acrylic restoration was used during the submerged period.

Second-stage surgery was performed 3 months after implant placement (Fig. 1B). In this parallel-group study design, randomly and based on allocation concealment, one of the implants was uncovered using a healing abutment (control group), while on the other implant, a standard final short abutment was seated and tightened to $30 \mathrm{Ncm}$ (test group) (Figs 1C and D). As the implants were initially placed $0.5 \mathrm{~mm}$ below the level of the crest, most of the implants were covered by crestal bone at secondstage surgery. Therefore, an osteotomy was needed to remove bone and uncover the platform, positioning the IN at crestal level [distance value between IN and first bone to implant contact (fBIC) equal to 0].
Six weeks after second-stage surgery, the final impression of the two implants was registered using polyether impression material (Impregum ${ }^{\mathrm{TM}} 3 \mathrm{M}$ ESPE AG, Germany), using the close tray technique. All 18 patients received a splinted two-unit cemented final prosthesis (Figs 1E and F). At each step of the prosthetic try-in, the abutment in the test group was removed and retightened to $30 \mathrm{Ncm}$. In all cases, the number of sessions for prosthetic work was limited to a maximum of four.

\section{Radiographic Follow-up}

Marginal bone levels were assessed through standardized periapical intraoral digital radiographs in the test and control group immediately after surgery and at 3, 6, 9 and 12 months follow-up examinations (Figs 2A to E). Radiographs were obtained using long-cone parallel projection and an image sensor holder. Radiographs that did not show clear implant threads were discarded and repeated.

Alveolar bone loss was measured at the mesial and distal sites of the implants from the implant-abutment interface to the crest of the alveolar bone using an automated image analysis program (Image J; NIH) to perform precise calibration and measurements.

For each pair of measurements, the mean value was used to compensate for the radiographic distortions. The scale in the image was set to the known distance of three consecutive implant threads $(3 \times 0.6=1.8 \mathrm{~mm})$.

To reduce the error, one examiner carried out all measurements twice, at a 2 -week interval. Comparing
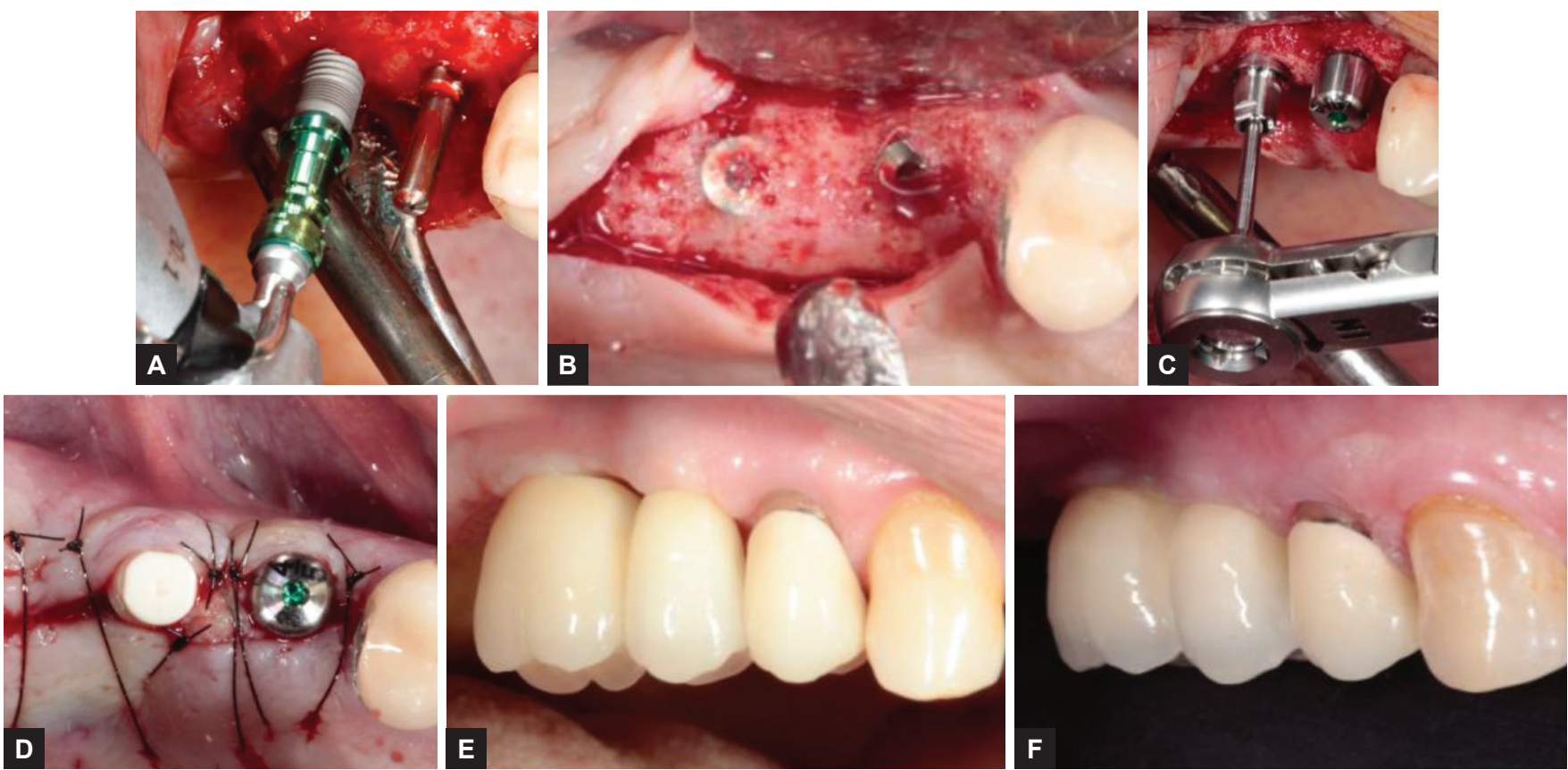

Figs $1 \mathrm{~A}$ to F: Clinical procedure steps: (A) Initial test and control dental implant placement; (B) Second-stage surgery showing no bone resorption 3 months following implant placement; (C) Tightening short abutment at $30 \mathrm{Ncm}$ on the test implant and placing of a standard healing abutment on the control implant; (D) Flap closure at second-stage surgery. The short abutment received a protective cap; (E) Final restoration 6 months after implant placement; (F) Clinical view 9 months after loading 


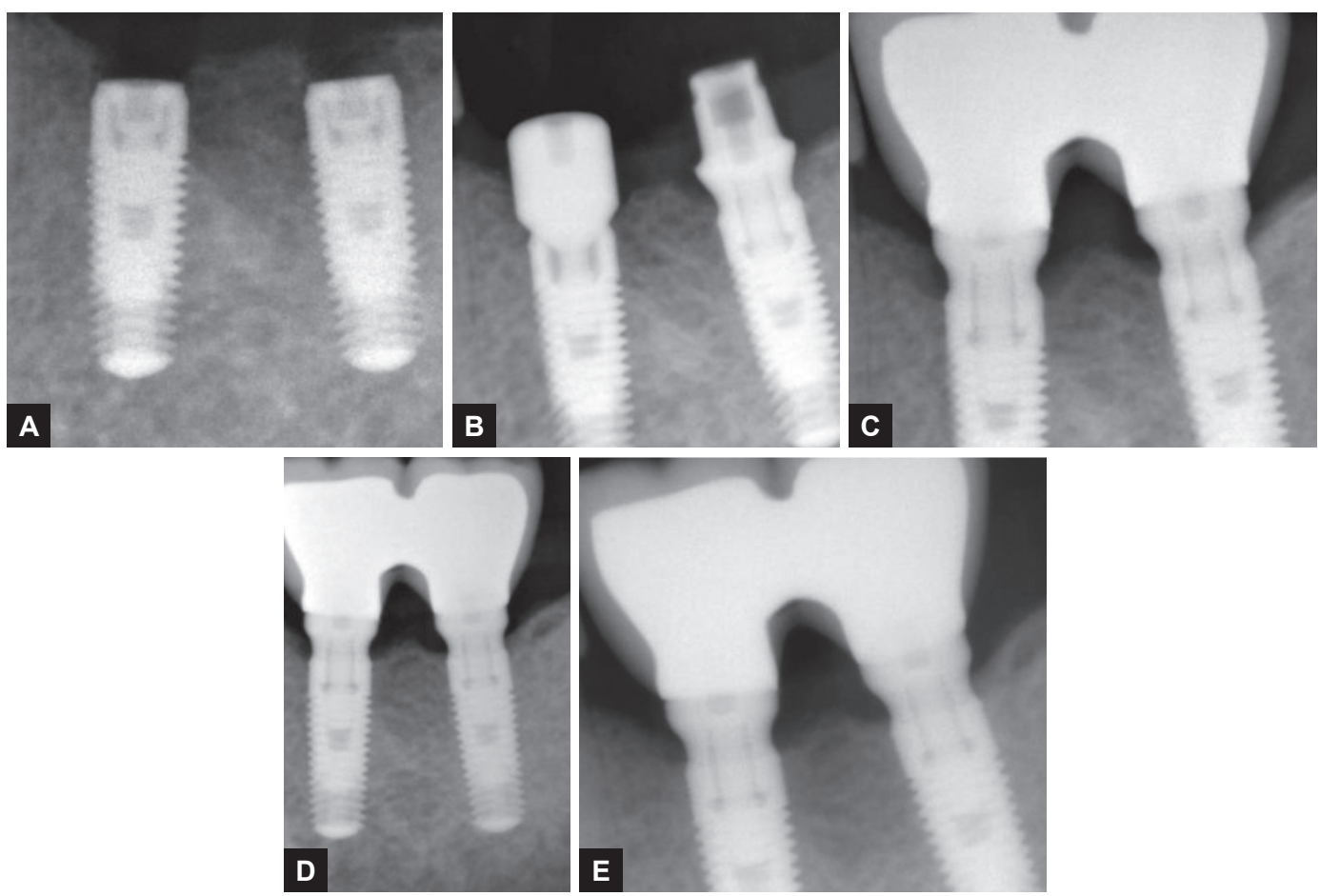

Figs 2A to E: Peri-apical radiographs at: (A) Day 0; (B) 3 months; (C) 6 months; (D) 9 months; (E) 12 months

the first and second set of measurements assessed the intraobserver error.

\section{Statistical Analysis}

Statistical analyses were conducted to evaluate differences in alveolar bone loss over time and between the control and test implants. Firstly, descriptive statistics including the mean, standard deviation, median, minimum and maximum values were calculated within each group and at each time point. Graphical methods including boxplots and histograms were used to evaluate the distribution of data. Shapiro-Wilk statistics were calculated to evaluate the normality of the data distributions.

A 4 (time) $\times 2$ (condition) within-subjects repeatedmeasures analysis of variance (ANOVA) was used to evaluate changes by time and condition. The outcome was average alveolar bone loss in millimeters (average of mesial and distal measurements). Pairwise comparisons using Bonferroni correction were used to evaluate where differences occurred.

Due to the small sample size and the failure of normality at some time points, analyses were repeated using nonparametric methods to evaluate the consistency of the findings. Friedman's test by ranks, the nonparametric analogue of the one-way repeated-measures ANOVA, was used to examine differences over time, and differences between the control and test conditions. These analyses were conducted separately, as Friedman's test assesses only one within-subjects variable at a time. The nonparametric analysis yielded results that confirm the parametric one; therefore, repeated-measures ANOVA was reported in this paper, as means are easier to interpret and compare than medians.

All statistical analyses were conducted using SPSS v. 20. Charts were created using Minitab v.16.1.1. An alpha level of 0.05 was used as a decision point for statistical significance.

\section{RESULTS}

There was no statistically significant intraobserver error.

An interclass correlation coefficient of 0.961 was obtained between the first and second sets of measurements, yielding a low intraexaminer error. Therefore, the second reading of each assessment was used in the statistical analyses.

Descriptive statistics for the two groups at each time point are reported in Table 1. It can be observed that the alveolar bone loss means in the control condition were higher than the means in the test condition at each time point. The medians at 3 months were markedly lower than the means in each condition, indicating skewed distributions.

Boxplots of the data distributions are provided in Graph 1 and histograms for the control and test conditions are depicted in Graphs 2 and 3 respectively.

\section{Effect of Time and Treatment on Marginal Bone Loss}

A repeated-measures ANOVA was used to assess the effects of time and condition and average bone loss. 
Marginal Bone Remodeling

Table 1: Descriptive statistics for average bone loss at 3, 6, 9 and 12 months for control and test conditions

\begin{tabular}{llllll}
\hline \multirow{2}{*}{ Month } & \multicolumn{4}{c}{ Average bone loss $(\mathrm{mm})$} \\
\cline { 3 - 6 } & & Control & \multicolumn{3}{c}{ Test } \\
& & 0.249 & $(0.362)$ & 0.197 & 0.262 \\
6 & M (SD) & 0 & $(0,0.975)$ & 0.075 & $(0,0.98)$ \\
& Med (Min, Max) & 0.773 & $(0.413)$ & 0.601 & $(0.386)$ \\
9 & M (SD) & 0.722 & $(0.185,1.485)$ & 0.513 & $(0.165,1.4)$ \\
12 & Med (Min, Max) & 0.904 & $(0.360)$ & 0.685 & $(0.341)$ \\
& M (SD) & 0.928 & $(0.240,1.675)$ & 0.577 & $(0.280,1.4)$ \\
& Med (Min, Max) & 1.047 & $(0.395)$ & 0.846 & $(0.454)$ \\
& M (SD) & 1.125 & $(0.350,1.755)$ & 0.7 & $(0.300,2.155)$ \\
\hline
\end{tabular}

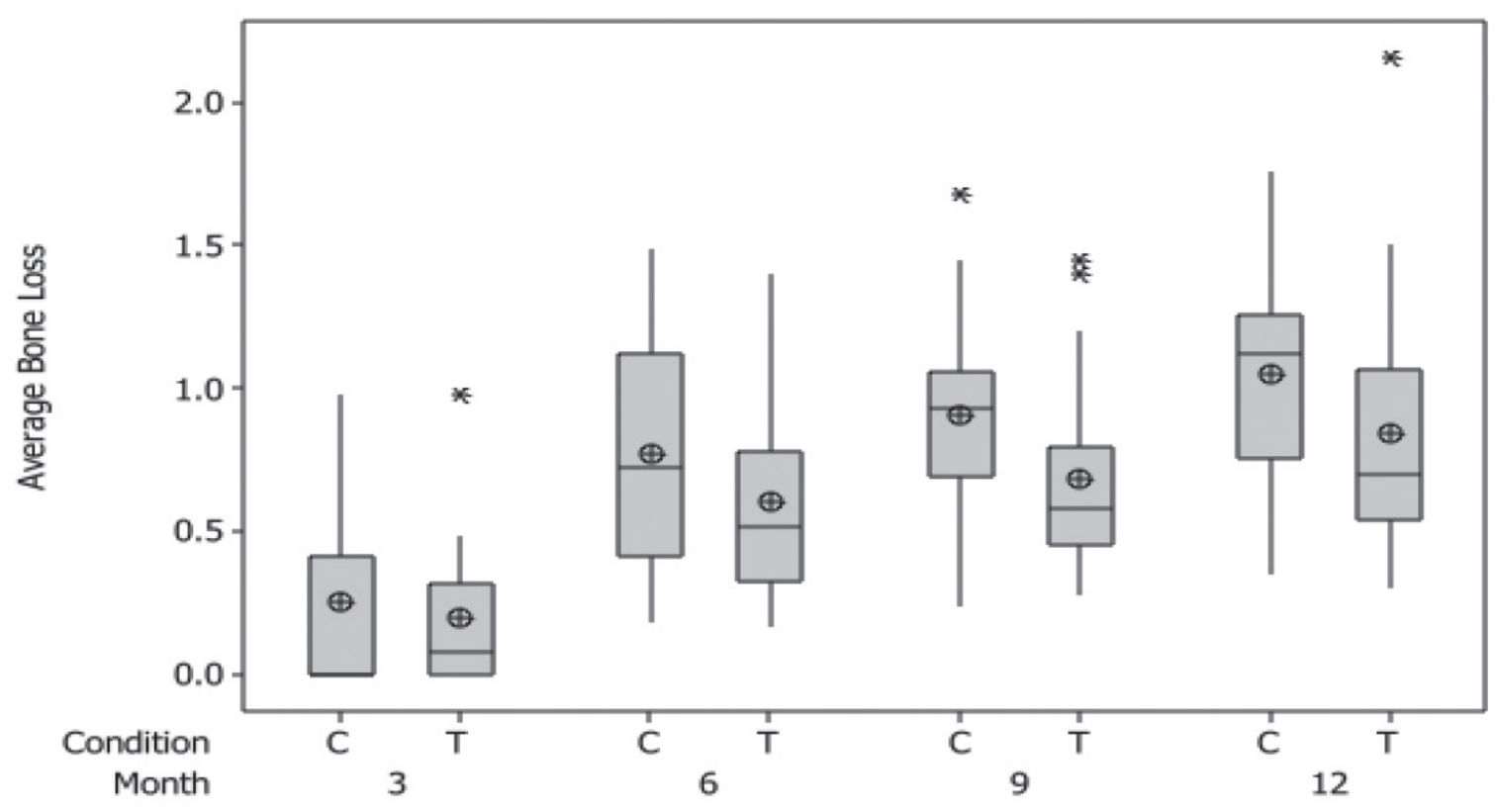

Graph 1: Boxplots of average bone loss in $\mathrm{mm}$ for control $(C)$ and test $(T)$ conditions at each time point. Horizontal lines denote the median and circles denote the mean. Asterisks indicate outliers
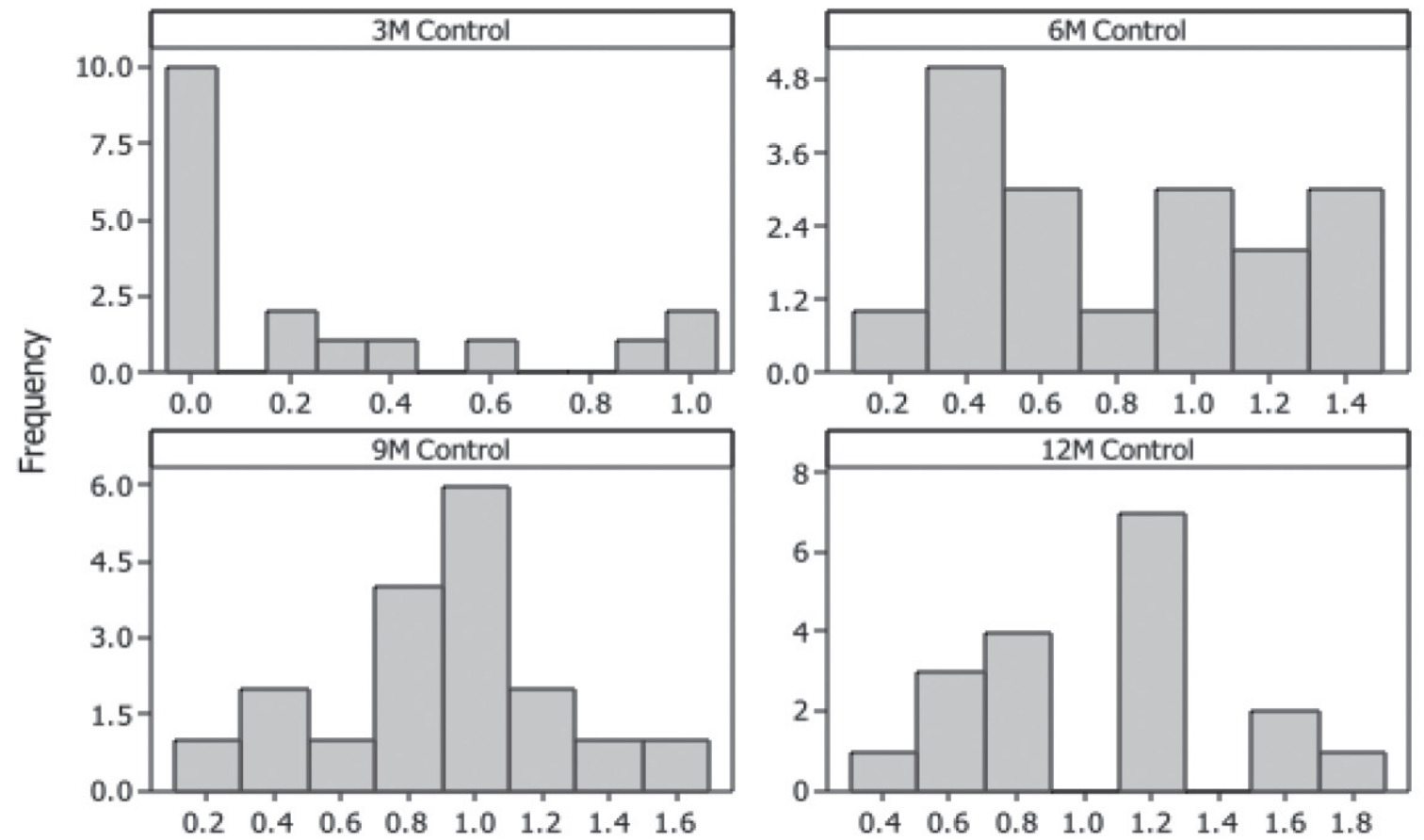

Graph 2: Histograms of data distributions at each time point for the control condition 


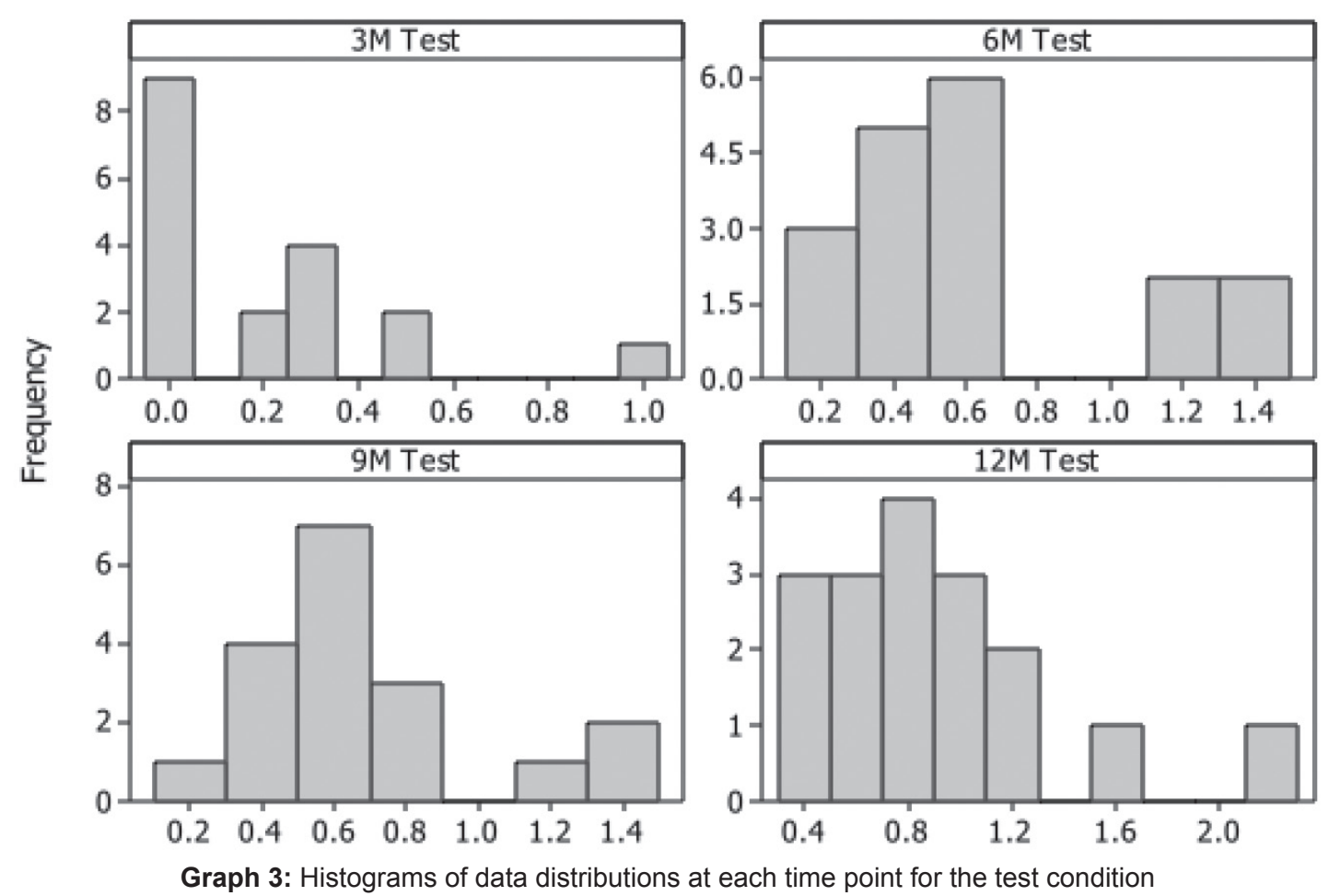

The two within-subjects variables were condition (two levels) and time (four levels). A full-factorial model was employed to examine their interaction. There were no between-subjects variables in the model. Pillai's trace was used to assess the multivariate effects. Pillai's trace is a positive-valued statistic, representing the proportion of variance in the multivariate dependent variable that is explained by the predictor. Increasing values indicate effects that contribute more to the model. Pillai's trace is often thought to be the most robust of the multivariate statistics to violations of model assumptions. ${ }^{10,11}$

The multivariate effects of the analysis are reported in Table 2. There was a significant main effect of condition $(p=0.005)$, and of time $(p<0.001)$ but no interaction between the two variables $(p=0.238)$. Pairwise comparisons (with Bonferroni correction) of main effects were conducted to evaluate the differences. Despite the lack of interaction term, pairwise comparisons of simple effects were also undertaken, due to the a priori interest to examine at what time point(s) differences occurred between the two conditions.

Results of the pairwise comparisons are summarized in Table 3. Firstly, with respect to the significant main

Table 2: Multivariate effects of condition, time and their interaction on average bone loss

\begin{tabular}{lllll}
\hline Variable & Pillai's trace & $F$ & $D f$ & $p$ \\
\hline Condition & 0.383 & $10.552^{*}$ & 1,17 & 0.005 \\
Time & 0.848 & $27.994^{*}$ & 3,15 & $<0.001$ \\
Condition* Time & 0.239 & 1.570 & 3,15 & 0.238 \\
\hline
\end{tabular}

${ }^{*} p<0.05$ effect of time (final column in Table 3), pairwise comparison of marginal means indicated that the mean bone loss at 3 months $(0.223 \mathrm{~mm})$ was significantly lower than the means at the other three time points, which did not differ from one another $(0.687 \mathrm{~mm}$ at $6 \mathrm{M}, 0.794 \mathrm{~mm}$ at $9 \mathrm{M}$ and $0.946 \mathrm{~mm}$ at $12 \mathrm{M}$ on average). Inspection of simple effects showed this pattern to be consistent in both the control and test conditions, with the average 3-month bone loss being significantly lower than the other time points.

Marginal comparison of the main effect of condition (final row in Table 3) indicated that the overall mean bone loss in the test group $(0.582 \mathrm{~mm})$ was significantly lower than the mean in the control group $(0.743 \mathrm{~mm})$. Comparison of simple effects indicated these differences were apparent at 9 and 12 months. Mean bone loss did not differ between the two conditions at 3 months. The

Table 3: Pairwise comparisons of marginal and simple effects relating to time and condition on alveolar bone loss

\begin{tabular}{llll}
\hline & \multicolumn{3}{c}{ Condition } \\
\cline { 2 - 4 } Month & Control & Test & Overall \\
\cline { 2 - 4 } & $M(S E)$ & $M(S E)$ & $M(S E)$ \\
\hline 3 & $0.249(0.085)^{a, 1}$ & $0.197(0.062)^{a, 1}$ & $0.223(0.069)^{a}$ \\
6 & $0.773(0.097)^{b, 1}$ & $0.601(0.091)^{b, 1}$ & $0.687(0.085)^{b}$ \\
9 & $0.904(0.085)^{b, 1}$ & $0.685(0.080)^{b, 2}$ & $0.794(0.075)^{b}$ \\
12 & $1.047(0.093)^{b, 1}$ & $0.846(0.107)^{b, 2}$ & $0.946(0.092)^{b}$ \\
Overall & $0.743(0.071)^{1}$ & $0.582(0.067)^{2}$ & $0.663(0.065)$ \\
\hline
\end{tabular}

Note. Means and standard errors at each time point (simple) and overall (marginal) are provided. Alphabetic subscripts denote significantly different column means at $p<0.05$ (Bonferroni correction). Numerical subscripts denote significantly different row means at $p<0.05$ (Bonferroni correction) 


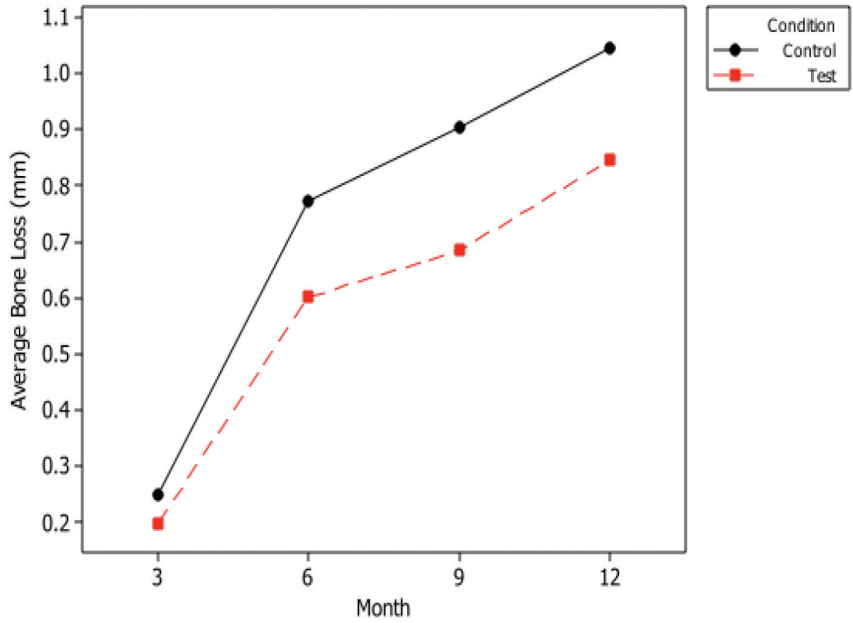

Graph 4: Mean bone loss in the control and test groups over time Bone loss significantly increased between 3 and 6 months for both conditions. Measurements taken between 6 and 12 months did not differ significantly. The mean bone loss in the control condition was significantly greater than in the test condition, with these differences being most apparent at the 9 and 12-month follow-up examinations.

significance value for the 6-month comparison of control and test means was $p=0.053$, thus narrowly missing the cut-off for statistical significance.

In summary, the results revealed that bone loss increased over time, with the greatest change in bone loss occurring between 3 and 6 months. Alveolar bone loss was significantly greater in the control than the test group, the latter having lower marginal bone loss of $20.88 \%$ at M3 (0.197 \pm 0.262$), 22.25 \%$ at M6 (0.601 \pm 0.386$), 24.23 \%$ at M9 (0.685 \pm 0.341$)$ and $19.2 \%$ at M9 (0.846 \pm 0.454$)$. The relationship between bone loss, time and condition is depicted in Graph 4.

\section{Clinical Data}

In this study, all 40 implants were successfully placed. Clinical stability was achieved and only one implant presented premature soft tissue exposure, leading to excessive marginal bone loss and was dropped out from the study. The same data set, based on radiographic evaluations, demonstrated that no per-implant radiolucency was found around the implants included in the present study. Thus, these implants achieved excellent hard tissue integration as assessed by clinical and radiographic means.

\section{DISCUSSION}

The periimplant bone level has been used as one of the criteria to assess the success of dental implants. It is an important prerequisite for preserving the integrity of gingival margins and interdental papillae. ${ }^{12}$ A radiographic marginal bone loss of $1.5 \mathrm{~mm}$ during the first year followed by a radiographic marginal bone loss of $0.2 \mathrm{~mm}$ during each succeeding year has been considered to be an important parameter for the assessment of implant success. ${ }^{13}$ The periimplant bone remodeling occurs once the implant is exposed to the oral environment in a second surgical procedure or in case of a nonsubmerged technique immediately after implant placement. The remodeling process involves marginal bone resorption that is affected by one or more of the following factors: (1) A traumatic surgical technique, ${ }^{14}$ (2) excessive loading conditions; ${ }^{15}$ (3) the location, shape and size of the implant-abutment microgap and its microbial contamination, ${ }^{16-18}$ and (4) the biologic width and soft tissue considerations. ${ }^{19-22}$

The purpose of this prospective, randomized controlled trial was to compare alveolar bone loss in control and test abutments, in a sample of 18 partially edentulous patients who each received two implants (one control, one test). Marginal bone levels were assessed mesially and distally at 3, 6, 9 and 12-month follow-up examinations. The average of mesial and distal measurements was considered as the outcome measure.

This within-subjects repeated-measures design was statistically evaluated using both parametric and nonparametric methods. Both methods yielded consistent findings, and subsequently, the parametric results were reported. Alveolar bone loss increased over time, with the changes occurring primarily between the 3-month and 6-month follow-up examinations.

The bone loss in the control condition (healing collar) was significantly greater than in the test condition (short abutment with friction-fit). Both conditions had similar results at 3 months, but the bone loss in the control condition exceeded that of the test condition as the length of follow-up progressed. After placement of the same final abutment in the test and control group, further increases in bone loss between 6 and 12 months were not statistically significant.

Jansen et $\mathrm{al}^{23}$ previously demonstrated that there is always a microgap of approximately $10 \mu \mathrm{m}$ between the abutment and the implant, irrespective of the implant system used. Histologic analysis has shown inflammatory infiltrate in the microgap. Rack et $\mathrm{al}^{24}$ showed that microgaps exist in the investigated conical implantabutment connection, with or without load application.

In another study, it was suggested that marginal bone level alterations could be related to the extent of implant/abutment mismatching. ${ }^{25}$ This study showed an inverse correlation between the extent of mismatching and the amount of bone loss. Therefore, although it has been shown that the seal provided by a locking taper connection at the implant-abutment interface effectively impairs bacterial leakage ${ }^{26}$ the size of the inflammatory infiltrate seems to be rather limited in 
size $^{27}$ on the order of $0.5 \mathrm{~mm}$ in diameter in $\operatorname{dogs}^{17}$ as well as in humans. ${ }^{28}$

Controversially, other studies by Hermann et $\mathrm{al}^{29}$ and King et $\mathrm{al}^{30}$ demonstrated in dogs that the size of the microgap between implants and abutments has a little influence on marginal bone remodeling, whereas micro movements of the abutments induce significant bone loss, independent of the microgap's size. This strongly suggests that the mechanical disruption of the soft tissue interface is of importance.

It has also been shown that five intentional abutment disconnections and reconnections (after alcohol disinfection) with monthly intervals induce an apical repositioning of the soft tissues and marginal bone resorption. ${ }^{31}$ In contrast, a single shift of a healing abutment and replacement by a final abutment proved to induce no marginal bone remodeling. ${ }^{32}$

Hermann et $\mathrm{al}^{33}$ also performed five disconnections of healing abutments in dogs with 1-month intervals, but without alcohol disinfection. They observed no noticeable influence. In the present study, the authors performed four abutment disconnections and reconnections during prosthesis fabrication for control and test group.

This strongly suggests that the statistical significant difference in bone loss occurring between the 3-month and 6-month follow-up examinations could mainly be due to the difference in implant abutment interface. The short abutment used in test group, once tightened till $30 \mathrm{Ncm}$, presents a friction fit internal hexagon with a modified design that has essentially eliminated all rotational misfit between the implant hex and the abutment. It consists of adding a $1^{\circ}$ taper to the hex flat and a corresponding close-tolerance hexagonal abutment recess that is frictionfitted onto the hex. ${ }^{34,35}$ In contrast, the healing collar used in the control group is not tightened to $30 \mathrm{Ncm}$ and does not present the same connection features leading to a higher micro movement and consequently to more marginal bone resorption.

The results of the present study showed that the use of a friction fit abutment during the try-in stages succeeded in reducing periimplant marginal bone loss in the period (between 3 and 6 months) preceding the final restoration when compared with a conventional healing collar placement. A recent literature review analysis by Schwarz et $\mathrm{al}^{36}$ revealed that the impact of the implant-abutment connection lacks documentation; the outcome of this study is contributing to solve this issue. In addition, this study clearly demonstrated the importance of a stable implant-abutment connection in reducing the micro movements that seems to be the main inducers of marginal bone remodeling. Whereas numerous studies demonstrated the role of different parameters such as the positioning of the smooth-rough interface, the size of microgap, the multiple abutment disconnections-reconnections, in periimplant bone resorption, this is the first study, as far as we know, that strongly evidenced the key role of the micro movements in early marginal bone loss. The findings of this study advise us to use a stable healing component since the early stages following implant placement. Ultimately, future healing abutment design should meet the characteristics of a stable connection.

\section{CONCLUSION}

Within the limitation of this study, the following conclusions may be drawn:

- The use of a stable connection in a healing component during try-in stages prior to final restoration placement demonstrated less periimplant marginal bone loss, when compared with placement of a conventional healing collar.

- It was noticed that marginal bone remodeling was a continuous phenomenon often in a positive way in a manner that marginal bone apposition occurred several months after loading in both test and control group.

Future large-scale studies are still warranted to confirm the results obtained in the present study.

\section{REFERENCES}

1. Esposito M, Ekestubbe A, Grondahl K. Radiological evaluation of marginal bone loss at tooth surfaces facing single Brånemark implants. Clin Oral Implants Res 1993 Sep;4(3):151-157.

2. Neart I, Koustsikakis G, Quirynen M, Duyck J, van Steenberghe D, Jacobs R. Biologic outcome of implant-supported restorations in the treatment of partial edentulism. Part 2: a longituadinal radiographic evaluation. Clin Oral Implants Res 2002 Aug;13(4):390-395.

3. Cehreli MC, Karasoy D, Kökat AM, Akça K, Eckert S. A systematic review of marginal bone loss around implants retaining or supporting overdentures. Int J Oral Maxillofac Implants 2010 Mar-Apr;25(2):266-277.

4. Abrahamsson I, Berglundh T. Effects of different implant surfaces and designs on marginal bone-level alterations: a review. Clin Oral Implants Res 2009 Sep;20(Suppl 4):207-215.

5. Bozkaya D, Muftu S, Muftu A. Evaluation of load transfer characteristic of five different implants in compact bone at different load levels by finite element analysis. J Prosthet Dent 2004 Dec;92(6):523-530.

6. Hermann JS, Schoolfield JD, Schenk RK, Buser D, Cochran DL. Influence of the size of the microgap on crestal bone changes around titanium implants. A histometric evaluation of unloaded non-submerged implants in the canine mandible. J Periodontol 2001 Oct;72(1):1372-1383.

7. Wiskott HWA, Belser UC. Lack of integration of smooth titanium surfaces: a working hypothesis based on strains generated in the surrounding bone. Clin Oral Implants Res 1999 Dec;10(6):429-444. 
8. Dhir S. Significance and clinical relevance of biologic width to implant dentistry. J Interdiscip Dentistry 2012;2:84-91.

9. Hermann JS, Buser D, Schenk RK, Schoolfield JD, Cochran DL. Biologic width around one- and two-piece titanium implants. A histometric evaluation of unloaded nonsubmerged and submerged implants in the canine mandible. Clin Oral Implants Res 2001;12:559-571.

10. IBM Corp. IBM SPSS Statistics for Windows, Version 20.0. [Computer software]. Armonk, NY: IBM Corp; 2011.

11. Tabachnick BG, Fidell LS. Using multivariate statistics (5th edition). Boston: Allyn and Bacon; 2006.

12. Desai MH, Patil VA. Platform switching: a panacea for bone loss? J Indian Soc Periodontol 2013 Sep;17(5):681-683.

13. Albrektsson T, Zarb G, Worthington P, Eriksson AR. The longterm efficacy of currently used dental implants: a review and proposed criteria of success. Int J Oral Maxillofac Implants 1986 Summer;1(1):11-25.

14. Oh TJ, Yoon J, Misch CE, Wang HL. The causes of early implant bone loss: myth or science? J Periodontol 2002 Mar; 73(3): 322-333.

15. Isidor F. Loss of osseointegration caused by occlusal load of oral implant. A clinical and radiographic study in monkeys. Clin Oral Implants Res 1996 Jun;7(2):143-152.

16. Todescan FF, Pustilioni FE, Imbronito AV, Albrektsson T, Gioso M. Influence of the microgap in the periimplant hard and soft tissues: a histomorphometric study in dogs. Int J Oral Maxillofac Implants 2002 Jul-Aug;17(4):467-472.

17. Broggini N, McManus LM, Hermann JS, Medina RU, Oates TW, Schenk RK, Buser D, Mellonig JT, Cochran DL. Persistent acute inflammation at the implant-abutment interface. J Dent Res 2003 Mar;82(3):232-237.

18. Broggini N, McManus LM, Hermann JS, Medina R, Schenk RK, Buser D, Cochran DL. Periimplant inflammation defined by the implant-abutment interface. J Dent Res 2006 May;85(5):473-478.

19. Hermann JS, Schoolfield JD, Schenk RK, Buser D, Cochran DL. Influence of the size of the microgap on crestal bone changes around titanium implants. A histometric evaluation of unloaded non-submerged implants in the canine mandible. J Periodontol 2001 Oct;72(1):1372-1383.

20. Berglundh T, Lindhe J. Dimension of the periimplant mucosa. Biological width revisited. J Clin Periodontol 1996 Oct;23(1):971-973.

21. Canullo L, Fedele GR, Iannello G, Jepsen S. Platform switching and marginal bone-level alterations: the results of a randomized-controlled trial. Clin Oral Implants Res 2010 Jan;21(1):115-121.

22. Lindhe J, Berglundh T. The interface between the mucosa and the implant. Periodontol 20001998 Jun;17:47- 54.

23. Jansen VK, Conrads G, Richter EJ. Microbial leakage and marginal fit of the implant-abutment interface. Int J Oral Maxillofac Implants 1997 Jul-Aug;12(4):527-540.
24. Rack T, Zabler S, Rack A, Riesemeier H, Nelson K. An in vitro pilot study of abutment stability during loading in new and fatigue-loaded conical dental implants using synchrotronbased radiography. Int J Oral Maxillofac Implants 2013 Jan-Feb;28(1):44-50.

25. Atieh MA, Ibrahim HM, Atieh AH. Platform switching for marginal bone preservation around dental implants: a systematic review and meta-analysis. J Periodontol 2010 Oct;81(10):1350-1366.

26. Cochran DL, Hermann JS, Schenk RK, Higginbottom FL, Buser D. Biologic width around titanium implants. A histometric analysis of the implanto-gingival junction around unloaded and loaded nonsubmerged implants in the canine mandible. J Periodontol 1997 Feb;68(2):186-198.

27. Buser D. Biologic width around titanium implants. A histometric analysis of the implanto-gingival junction around unloaded and loaded nonsubmerged implants in the canine mandible. J Periodontol 1997 Feb;68(2):186-198.

28. Canullo L, Pellegrini G, Allievi C, Trombelli L, Annibali S, Dellavia C. Soft tissues around long-term platform switching implant restorations: a histological human evaluation. Preliminary results. J Clin Periodontol 2011 Jan;38(1):86-94.

29. Hermann JS, Schoolfield JD, Schenk RK, Buser D, Cochran DL. Influence of the size of the microgap on crestal bone changes around titanium implants. A histometric evaluation of unloaded non-submerged implants in the canine mandible. J Periodontol 2001 Oct;72(10):1372-1383.

30. King GN, Hermann JS, Schoolfield JD, Buser D, Cochran DL. Influence of the size of the microgap on crestal bone levels in non-submerged dental implants: a radiographic study in the canine mandible. J Periodontol 2002 Oct;73(1):1111-1117.

31. Abrahamsson I, Berglundh T, Lindhe J. The mucosal barrier following abutment dis/reconnection. An experimental study in dogs. J Clin Periodontol 1997 Aug;24(8):568-572.

32. Abrahamsson I, Berglundh T, Sekino S, Lindhe J. Tissue reactions to abutment shift: an experimental study in dogs. Clin Implant Dent Relat Res 2003;5(2):82-88.

33. Hermann JS, Jones AA, Bakaeen LG, Buser D, Schoolfield JD, Cochran DL. Influence of a machined collar on crestal bone changes around titanium implants: a histometric study in the canine mandible. J Periodontol 2011 Sep;82(9):1329-1338.

34. Binon PP. Implants and components: entering the new millennium. Int J Oral Maxillofac Implants 2000 Jan-Feb;15(1): 76-94.

35. Binon PP. The evolution and evaluation of two interference-fit implant interfaces. Postgraduate Dent 1996;2:1-15.

36. Schwarz F, Alcoforado G, Nelson K, Schaer A, Taylor T, Beuer F, Strietzel FP. Impact of implant-abutment connection, positioning of the machined collar/microgap, and platform switching on crestal bone level changes. Camlog Foundation Consensus Report. Clin Oral Implants Res 2014 Nov;25(11):1301-1303. 